\title{
Study on Financing Mode Innovation in New Urbanization Construction of the Yangtze River Economic Belt
}

\author{
Qiong Wu \\ Wuhan Donghu University, Wuhan 430212, China \\ wuqiong@163.com
}

Keywords: Yangtze River Economic Belt; New Urbanization; Financing Mode

\begin{abstract}
From the perspective of new urbanization construction of the Yangtze River economic belt, in this paper we firstly analyze the financing demand of it, and then describe the disadvantages of the traditional mode of financing, and finally explore how to construct diversified and sustainable urbanization financing mechanism. Financing is one of the key links in the construction of urbanization. However, because financial investment of traditional financing mode cannot meet the requirements, and "land finance" is unsustainable, it would bring huge debt risk to local financing platform, greatly restricting the promotion of new urbanization. The new market-oriented financing needs certain basic conditions, and meanwhile there are also some risks. In view of this, new urbanization construction of Yangtze River economic belt should proceed from reality, to create a variety of market financing conditions while regulating traditional financing mode. The objective is to build the new market-oriented financing mode of diversified investment subject and financing way, and implement different combinations of financing in different regions inside and outside the province.
\end{abstract}

\section{Introduction}

In September 25, 2014, China's State Council released "Guidance on the development of the Yangtze River Economic Belt based on the golden waterway”, Clearly stating that, the Yangtze River Economic Belt covers 11 provinces of Shanghai, Jiangsu, Zhejiang, Anhui, Jiangxi, Hubei, Hunan, Chongqing, Sichuan, Yunnan and Guizhou, with an area of about 2,050,000 square kilometers, where the population and GDP are both more than $40 \%$ of the national total. Yangtze River Economic Belt stretches across three regions of China, and has unique advantages and great development potential. Since the reform and opening up, Yangtze River Economic Belt has become one of the largest areas of our country with strongest comprehensive strength, strategic support role. In the background that international environment has undergone profound changes and domestic development faces many contradictions, to promote the development of Yangtze River Economic Belt will help tap the huge potential of domestic demand contained in the vast hinterland upper and middle Yangtze River, and promote quality and efficiency of China's economy.

New urbanization of Yangtze River Economic Belt refers to follow along the ideas of gathering along the river, group development, interactive collaboration and adaptation to local condition, to carry forward the new urbanization of human-centered, to optimize the layout and form of urbanization, to enhance capacity for sustainable development of cities, to innovate the mechanisms for the development of urbanization, so that comprehensively improve the urbanization quality of the Yangtze River Economic Belt. To promote the development of Yangtze River Economic Belt and create Chinese new economic support belt is a major strategic decision made by China's State Council, which benefits both current and long-term. Under the background of this strategy, to conduct study on financing mode innovation in new urbanization construction of the Yangtze River Economic Belt is of great theoretical and practical significance 


\section{Financing Demand in New Urbanization Construction of the Yangtze River Economic Belt}

New urbanization construction of the Yangtze River Economic Belt undertakes the important mission of expanding domestic demand and stimulating the economic growth. Shown as the Nassem curve in economics (Fig. 1), when the urbanization level is more than 30\%, the first turning point emerges, indicating extremely rapid economic development momentum of the high-speed stage. Currently, China's development pace of urbanization is quite rapid, and its urbanization level is in this fast rising phase. However, China's urbanization construction is facing various aspects of financing demand problems, especially with the proposal of the Yangtze River Economic Belt strategy. In the future, its new urbanization development is faced with rising labor costs, and meanwhile because government pays more emphasis on people-centered, the funding needs in terms of social security system, infrastructure and utilities will be more and more rampant.

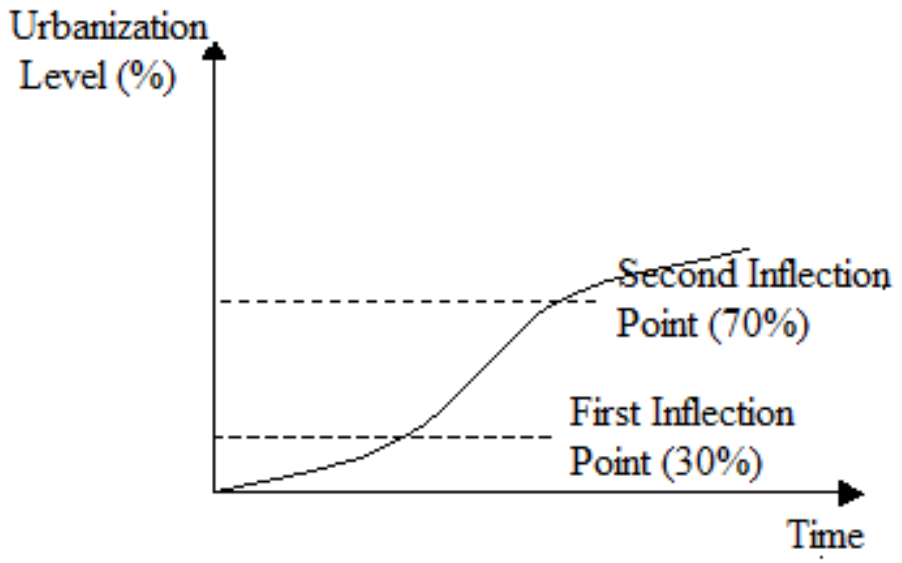

Fig. 1 Nassem curve

Financing Demand for Infrastructure. Urbanization construction of Yangtze River Economic Belt requires a lot of infrastructure construction funds. Infrastructure construction has the so-called "multiplier effect", that is, it can bring much aggregate demand and national income as several times as its investment. Whether the infrastructure construction in urbanization construction of Yangtze River Economic Belt is decent, is an important foundation for the economic long-term sustainable and stable development. The large fund demand in urban infrastructure construction, long funding cycle and limited economic benefits are the main issues of financing demands.

Financing Demand for Public Service. Public service is mainly to meet some immediate needs of Civic life, survival and development, binging citizens with benefits and enjoyment. Social public services mainly include education, science popularization, health care, social security environmental protection and other fields. The main supplier of public services should be government, and other social organizations can be as a supplement to when the government is insufficient. Obviously, public service needs a lot of funds to be smoothly provided.

Financing Demand for Industry Cluster. To accelerate the urbanization construction of Yangtze River economic belt, construction of industrial parks is the objective need of institutional innovation and foster new advantages of regional competition, which requires financial institutions to adapt to and serve the upgrade, agglomeration and adjustment of industrial structure. Funds shortage has become one of the major bottlenecks to restrict the development of gathering area economy.

Financing Demand for Resident's Comprehensive Development. Labor structure conversion, rural land capitalization, residents' income increase, income structure diversification and other dynamic adjustment, has brought the change in financial needs of resident's comprehensive development. Next ten years, China's new urban population will reach about four hundred million. If calculate at the average citizenship costs of one hundred thousand Yuan, it will need at least huge amounts of money of about 40 trillion $\sim 50$ trillion Yuan. Financing demand for residents comprehensive development mainly focus on the minimum funding requirement to transform the 
existing quasi -residents into real residents in aspects of identity, ideology, social rights and the way of life.

\section{Disadvantages of the Traditional Financing Mode in Urbanization Construction of the Yangtze River Economic Belt}

Financing in urbanization construction of The Yangtze River Economic Belt is mainly used in terms of infrastructure construction, public services, industry cluster, and resident's comprehensive development. Along with the push of the Yangtze River Economic Belt development strategy, traditional financing mode has been unable to meet the huge funds demand of new urbanization, and financing is facing serious difficulties, with huge fiscal and financial risks.

Investment Subject Is Unitary. At present, financial investment still account for a large proportion in the urban infrastructure construction. There is no doubt that, the financial resources is quite limited, and parts of the local fiscal revenue growth have begun to appear to decline significantly. Taking one city in Hubei as example, in 2012, its total local budget revenue was 6.564 billion, falling by 10.5 percent than last year. Correspondingly, the city's investment in fixed assets was as high as 75.085 billion, with year-on-year growth of $54.9 \%$. There was one huge funding gap while the emergence of new growth in the number of construction projects in 2013. In this case, relying solely on the financial investment obviously cannot meet the needs of rapid urbanization and infrastructure development.

Township Taxation Distribution Is Uneven. It requires a lot of funds to promote the urbanization, but most of urbanization projects are borne by the township government. From a practical point of view, to speed up the construction of industrial park and infrastructure, requires a lot of money. However, the sharing ratio of township finance is relatively low, and township taxation is mostly turned over, so the township government cannot invest more because of financial constraints. In addition, the investment and financing channels are not smooth, so the private capital is hard to transform into industrial capital and urban construction funds.

Guarantee System Is Imperfect. The premise of industry support force enhancement in small towns is rapid development of small and micro businesses. Financing difficulties is a bottleneck of to restrict the development of small and micro enterprises, while loans difficulty and guarantee difficulty is even more significant. Guarantee has the function of economic levers, and compared with discount, duty free, appropriation, investment and other policy financial support approach, guarantee can meet more demand with less investment, allowing policy funds to play bigger role in industrial development of small towns. Meanwhile, credit guarantee institutions through servicing for urbanization business, make up for its lack of credit and solve business financing problems, which will not only achieve their own economic benefits, but also reflect in promotion of the comprehensive benefits of urbanization development. Currently, the defect of guarantee system concretely performs as: first, the credit guarantee industry related laws and regulations are not perfect; second, guarantee agencies are mostly small scale, lack of risk dispersion and compensation system; third, operation of guarantee organization exist irregularities.

There Are Potential Financial Risks. In new urbanization construction, with rapid expansion of the number of local financing platform and rapid growth of the size of loans, related issues gradually appear, and the potential financial risks deserve to be concerned. The risk of local government financing platform include: the solvency risk because of high debt ratio and lack of repayment sources; project risk because of low investment benefits and undefined debt subject; credit risk because of unregulated loan capital flows.

\section{Measures to Construct Suitable Financing Mechanism for Urbanization Construction of Yangtze River Economic Belt}

To sum up the experience and lessons of domestic and foreign urban construction financing, we analyze the current bottleneck in new urbanization construction of China's Yangtze River Economic Belt. We believe that it needs to introduce and improve the market-oriented financing mode in the 
future, making comprehensive use of multi ways of municipal bonds issuance, multi-level capital market development, central financial support enhancement, public utilities investment fund establishment and so on, to solve the financing problem in new urbanization construction.

Cultivate and Develop Diversified Financing Body. In new urbanization construction of Yangtze River Economic Belt, it needs to continually update the concept of financing, to optimize the investment and financing environment, and cultivate and develop diversified financing body. The specific policy recommendations include: deepen the reform of financing system, to foster private investment subject; project financing and approval system reform to expand investment area; dominated by government and operated by market; foster financial intermediary services market; promote capital market financing; guide and regulate the small loan companies; try to establish a private trust and investment regime of large projects; establish and develop the venture capital industry, to expand the investment demand.

According to the project distinguish theory, financing projects can be divided into three categories: non-business class, quasi-business class and business class, as shown in Table 1:

Table 1. Project properties, financing body and financing way

\begin{tabular}{|c|l|l|l|}
\hline Project properties & \multicolumn{1}{|c|}{ Financing body } & \multicolumn{1}{|c|}{ Financing way } & \multicolumn{1}{c|}{ Examples } \\
\hline Non-business class & Government & $\begin{array}{l}\text { Government financing } \\
\text { (investment budget } \\
\text { plan, tax, etc.) }\end{array}$ & $\begin{array}{l}\text { Square, public green } \\
\text { space, basic pension, } \\
\text { medical care and } \\
\text { public health, etc. }\end{array}$ \\
\hline $\begin{array}{c}\text { Quasi-business } \\
\text { class }\end{array}$ & $\begin{array}{l}\text { Multiple financing body } \\
\text { (private investment, } \\
\text { government subsidy) }\end{array}$ & $\begin{array}{l}\text { Public private } \\
\text { partnerships, capital } \\
\text { market financing, etc. }\end{array}$ & $\begin{array}{l}\text { Water, electricity, } \\
\text { heating, etc. }\end{array}$ \\
\hline Business class & $\begin{array}{l}\text { Multiple financing body } \\
\text { (private investment, } \\
\text { government subsidy) }\end{array}$ & & Toll road, bridge, etc. \\
\hline
\end{tabular}

Deepen Fiscal And Tax Reform. With the speeding up of urbanization process in China the Yangtze River Economic Belt, local government bears a lot of responsibility in infrastructure construction and public service supply, which has led to mismatch of property rights, financial resources and powers. Deepen fiscal and tax reform, so that solve some deep-seated problems of public finance system, including transfer payment system improvement, basic public service investment, etc.

Improve the Guarantee System. Normalization of small and medium-sized enterprise credit guarantee institutions is directly related to the enterprise financing environment in urbanization construction of Yangtze River Economic Belt. To solve the financing problems in industrialization development of small cities and towns, it needs to add more financial support and compensation, so as to promote construction of credit system and security agencies information, and strengthen the credit guarantee industry activist and self-discipline. Since small micro-enterprise credit guarantee is with strong industry policy and salient social benefits, government should establish special funds for the development of small and micro enterprises, especially for the development of credit guarantee industry. Meanwhile, government could guide private capital for small and micro enterprise credit guarantee system construction.

Regulate Local Government Financing Platform. Combined with the background of the economic development of Yangtze River Economic Belt, in the process of new urbanization construction, it requires to seriously regulating the local government financing platform. Should establish and perfect the management mechanism of local government debt, actively promote the market-oriented operation of local government financing platform, and strengthen the supervision of local government financing platform through multi-sectorial linkage, developing financing law and studying on the long-term healthy development mode of the platform. To improve the marketization degree of financing platform, to improve the operation efficiency and management efficiency in the use of market mechanisms, is an effective way to reduce the risk. 
Adopt Capital Financing Method. In the process of China's new urbanization construction, to construct multi-level capital market is a breakthrough to effectively dock financial and real economy. He Qiang, director of Futures and Securities Institute of Central University of Finance and Economics, believes that multi-level capital market promote the rational flow of social capital, and improve the situation of virtual capital flooding and real economy shortage. The infrastructure construction projects in the process of urbanization generally have the features of long construction period, huge funds demand and high sunk costs, etc. The capital market-oriented direct financing is more suitable for new urbanization construction of Yangtze River Economic Belt, so it needs to vigorously develop the capital market and neatly apple various capital financing means.

In summary, vigorous development of Yangtze River Economic Belt is a new engine of China's continued economic growth in the future. To safely promote the new urbanization construction of Yangtze River Economic Belt, we have to properly handle the financing problem of new urbanization, and by summarizing the existing financing problems, construct scientific and effective financing innovation mode.

\section{References}

[1] Swyngedouw E, Moulaert F, Rodriguez A. Neoliberal urbanization in Europe: large-scale urban development projects and the new urban policy. Antipode, 2002, 34(3): 542-577.

[2] Zhang P, Ma Y, Liu W, et al. New Urbanization Strategy for Revitalizing the Tradianal Industrial Base of Northeast China. Acta Geographica Sinica, 2004: S1.

[3] Baoxing Q. The Urbanization Mode of the Towns with Chinese Features_-Mode C: Surpassing the Interesting of Mode A and Trap of Mode B. Urban Studies, 2009, 1: p2-7.

[4] Chen X, Liu J. The Research on the Finance Structure and Modes of Small and Medium Enterprises in the Different Growing Periods. Journal of Industrial Engineering and Engineering Management, 2006, 1: 000.

[5] Lifu F A N. Research on the Financial Support to the Urbanization in Rural Areas. Urban Studies, 2010, 7: 013 